\title{
Preparation and characterization of histone $\mathrm{H} 1$ from the sperm of the sea-urchin Sphaerechinus granularis
}

\author{
Vincenzo GIANCOTTI, ${ }^{*}$ Simonetta COSIMI, ${ }^{*}$ Peter D. CARY, $\dagger$ Colyn CRANE-ROBINSON† and \\ Giuseppe GERACI $\ddagger$ \\ *Istituto di Chimica, Università degli Studi di Trieste, Piazzale Europa 1, 34127 Trieste, Italy, †Biophysics \\ Laboratories, St. Michael's Building, Portsmouth Polytechnic, White Swan Road, Portsmouth PO1 2DT, U.K., \\ and $\ddagger$ Laboratorio di Embryologia Moleculare, C.N.R., 80072 Arco Felice, Napoli, Italy
}

(Received 15 September 1980/Accepted 29 December 1980)

\begin{abstract}
The separation and purification of histone $\mathrm{H} 1$ from the sperm of the sea-urchin Sphaerechinus granularis is described. Physical studies were used to compare this histone $\mathrm{H} 1$ molecule with $\mathrm{H} 1$ histones from other species. C.d. and $270 \mathrm{MHz}$ n.m.r. spectroscopy indicate that, despite significant compositional differences from other sea-urchin sperm $\mathrm{H} 1$ histones, their secondary and tertiary structures are very similar. A large difference in helicity was, however, found between $S$. granularis histone $\mathrm{H} 1$ and calf thymus histone $\mathrm{H} 1$, and their n.m.r. and fluorescence spectra also differ considerably. It is concluded that secondary structure and tertiary structure have not been conserved in the evolution of the $\mathrm{H} 1$ histone family.
\end{abstract}

Nucleosomal coiling or folding induces the formation of a fibre of diameter about $20-35 \mathrm{~nm}$ (Ris \& Kubai, 1970; Finch \& Klug, 1976; Suau et al., 1979), and it is generally assumed that histone $\mathrm{H} 1$ is responsible for the formation and maintenance of this structure in vivo (Littau et al., 1965; Bradbury et al., 1973; Finch \& Klug, 1976; Renz et al., 1977). Histone $\mathrm{H} 1$ consists of three structural domains. The central domain of approx. 80 residues is strongly conserved and serves to locate the molecules, whereas the flanking domains show much lower sequence conservation (Allan et al., 1980).

Sea-urchin sperm contains histones bound to the DNA rather than protamine-like proteins, and the histone $\mathrm{H} 1$ molecule in this tissue differs from 'conventional' (e.g. calf thymus) histone $\mathrm{H} 1$ in having a high arginine content, more aromatic residues and histidine. Sequence comparison of the histone $\mathrm{H} 1$ molecule from the sperm of the seaurchin Parechinus angulosus with that of calf thymus histone $\mathrm{H} 1$ shows the presence of considerable homology, but indicates that differences occur throughout the whole of the length of the molecule (Strickland et al., 1980). Sperm is also a terminally differentiated tissue, and its histone $\mathrm{H} 1$ molecule shows homologies with histone H5 also, particularly with regard to the content and position of the arginine residues. The present paper describes the preparation and purification of histone $\mathrm{H} 1$ from the sperm of a sea-urchin not studied before. The histone $\mathrm{H} 1$ molecule shows significant compositional differences. Physical measurements are used to look for similarities with and differences from other sea-urchin $\mathrm{H} 1$ histones and calf thymus histone $\mathrm{H} 1$. The structural approach to an understanding of the operation of histone $\mathrm{H} 1$ in chromatin is important in the absence of a functional assay of histone $\mathrm{H} 1$ action, i.e. it is hoped that, by the detailed analysis of structure in a wide range of histone $\mathrm{H} 1$ types, significant clues can be obtained as to their function and mode of action.

\section{Experimental}

\section{Preparation of histone $\mathrm{HI}$}

Total histone was extracted from the sperm of the sea-urchin Sphaerechinus granularis by acid extraction by using the method of Geraci \& Noviello (1979). Partial purification was obtained by chromatography on a Bio-Gel P-60 column $(2.5 \mathrm{~cm} \times$ $100 \mathrm{~cm})$ at $4{ }^{\circ} \mathrm{C}$. Samples $(300 \mathrm{mg})$ of total histone were loaded in $20 \mathrm{~mm}-\mathrm{HCl} / 50 \mathrm{mM}-\mathrm{NaCl} / 6 \mathrm{M}$-urea and eluted by $20 \mathrm{~mm}-\mathrm{HCl} / 50 \mathrm{~mm}-\mathrm{NaCl}$ (Van der Westhuyzen et al., 1974) at a flow rate of $3-8 \mathrm{ml} / \mathrm{h}$. Absorbance at $280 \mathrm{~nm}$ was used to monitor the elution pattern. Gel electrophoresis in $15 \%$ polyacrylamide containing $0.1 \%$ sodium dodecyl sulphate was used to check the purity of the eluted peaks. A large peak at the void volume contained aggregates of histones $\mathrm{H} 3$ and $\mathrm{H} 4$, and the histone $\mathrm{H} 1$ 
was found in the second peak at $V_{\mathrm{e}} / V_{0}=1.50$ together with histone $\mathrm{H} 2 \mathrm{~A}$. The last peak eluted was pure histone $\mathrm{H} 2 \mathrm{~B}_{1}$.

Histone $\mathrm{H} 1$ was purified from the histone $\mathrm{H} 1 /$ H2A mixture by ion-exchange chromatography on a Whatman CM-52 CM-cellulose column $(0.9 \mathrm{~cm} \times$ $15 \mathrm{~cm}$ ) equilibrated and eluted with $50 \mathrm{~mm}$-sodium acetate ( $\mathrm{pH} 4.5) / 6 \mathrm{M}$-urea. A linear salt gradient of $0-0.5 \mathrm{M}-\mathrm{NaCl}$ was used to separate the two components. The histone $\mathrm{H} 2 \mathrm{~A}$ was eluted at $0.22 \mathrm{M}$ $\mathrm{NaCl}$ and the histone $\mathrm{H} 1$ at $0.36 \mathrm{M}-\mathrm{NaCl}$. It is noteworthy that histone $\mathrm{H} 1$ is eluted after histone $\mathrm{H} 2 \mathrm{~A}$, rather than before as is found with calf thymus histones. This is presumably due to the higher content of arginine residues in the sea-urchin histone H1.

\section{Amino acid analysis}

A $1 \mathrm{mg}$ sample of protein was hydrolysed in $6 \mathrm{M}-\mathrm{HCl}$ for $20 \mathrm{~h}$ at $105^{\circ} \mathrm{C}$, and multiple analyses were performed at the Institute of Organic Chemistry, Padova, Italy, on a JEOL JLC 6AH analyser.

\section{Circular dichroism}

C.d. spectra were obtained on Jouan II and Cary 61 dichrographs. The approximate concentration of stock solutions of protein was obtained by weighing freeze-dried protein, and the accurate concentration was measured from the tyrosine absorbance at $276 \mathrm{~nm}$, assuming an absorption coefficient of $1340 \mathrm{~cm}^{-1} \cdot(\mathrm{mol} \text { of tyrosine })^{-1}$ and the presence of two tyrosine residues in a polypeptide chain of 250 residues. Each point in the c.d. spectra of Fig. 1 comes from measurement of a separate solution, adjusted to the desired molarity of $\mathrm{NaCl}$. A single stock solution was used for the data presented in Fig. 1, but the results were checked with a second, independent, preparation of $S$. granularis histone H1.

\section{Fluorescence}

Fluorescence spectra were measured in quartz cylindrical cells of $0.5 \mathrm{~cm}$ diameter on a PerkinElmer MPF/3L spectrofluorimeter. Excitation was at $280 \mathrm{~nm}$ and emission was monitored at $305 \mathrm{~nm}$. Emission intensity is reported as $R_{\mathrm{Tyr}}$, the observed intensity with respect to that from a solution of tyrosine amino acid at the same concentration in $0.1 \mathrm{M}$-Tris/ $\mathrm{HCl}$ buffer, pH 7.0 (Giancotti et al., 1977). The solutions used for the fluorescence data of Fig. 1 were the same as those used for the c.d. measurements.

\section{Electrophoresis}

Electrophoretic separations were performed in $15 \%$ polyacrylamide gels (acrylamide/bisacrylamide ratio $66: 1)$ essentially by method of Laemmli (1970) with the modifications described by Thomas \& Kornberg (1975).

\section{Nuclear magnetic resonance}

The $270 \mathrm{MHz}$ n.m.r. spectra were obtained on a Bruker WH270 instrument, equipped with an Oxford Instruments 6.4T superconducting magnet. Solutions of approx. $10 \mathrm{mg}$ of protein $/ \mathrm{ml}$ in $99.7 \%$ ${ }^{2} \mathrm{H}_{2} \mathrm{O}$ in $5 \mathrm{~mm}$ tubes were referenced with respect to internal sodium 4,4-dimethylsilapentanesulphonate.

\section{Results}

\section{Composition and molecular weight}

Table 1 gives the amino acid analysis of $S$. granularis histone $\mathrm{H} 1$ together with those of two other sea-urchin histone $\mathrm{H} 1$ molecules, histone $\mathrm{H} 1$ from calf thymus and histone $\mathrm{H} 5$ of chicken erythrocytes. It is noteworthy that the arginine content of $S$. granularis histone $\mathrm{H} 1$ is even higher than those of the other two sea-urchin $\mathrm{H} 1$ histones given,

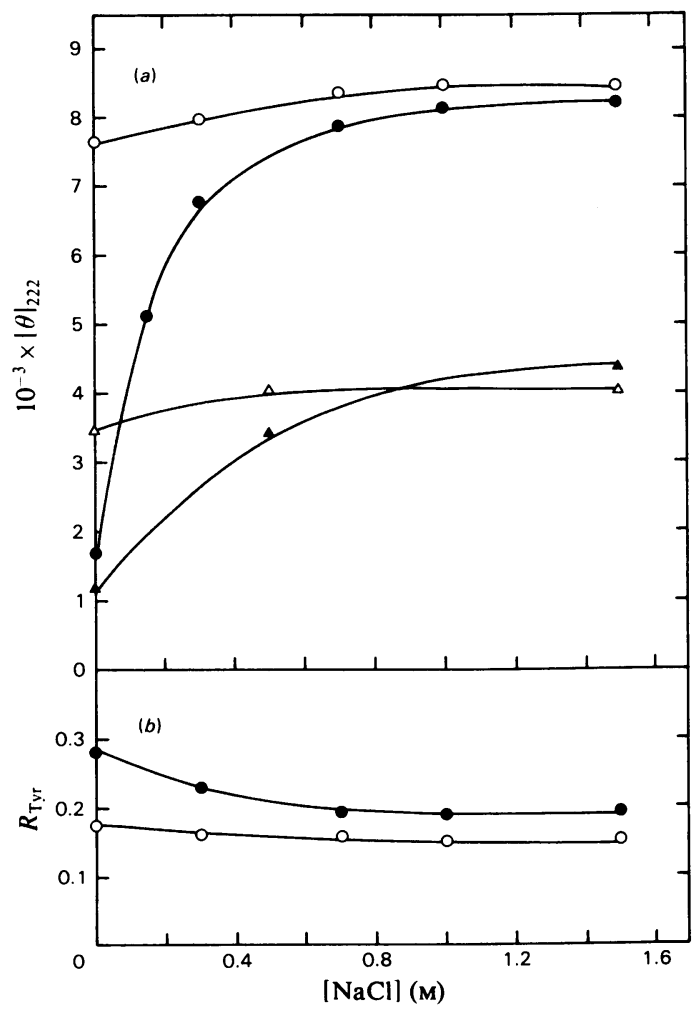

Fig. 1. C.d. (a) and fluorescence (b) data for $S$. granularis histone $H 1$ at $p H 3.5$ (O) and at pH 7.5 (O) in $10 \mathrm{mM}$-sodium phosphate buffer as a function of ionic strength

C.d. data for calf thymus histone $\mathrm{H} 1$ are shown for comparison at $\mathrm{pH} 3.5(\Delta)$ and at $\mathrm{pH} 7.5(\triangle)$. 
Table 1. Amino acid analysis of $H 1$ and $H 5$ histones from different sources

Italicized values for $S$. granularis histone $\mathrm{H} 1$ are for residue contents showing significant differences from those of $A$. lixula and $P$. angulosus $\mathrm{H} 1$ histones.

Amino acid composition (residues $/ 100$ residues)

\begin{tabular}{|c|c|c|c|c|}
\hline \multirow[b]{2}{*}{$\begin{array}{l}\text { Calf thymus } \\
\text { histone H1 } \\
\text { (Johns, 1971) }\end{array}$} & \multirow[b]{2}{*}{$\begin{array}{c}\text { Chicken erythrocyte } \\
\text { histone H5 } \\
\text { (Greenaway \& } \\
\text { Murray, 1971) }\end{array}$} & \multicolumn{3}{|c|}{ Sea-urchin sperm histones $\mathrm{H} 1$} \\
\hline & & $\begin{array}{c}\text { Arbacia lixula } \\
\text { (Puigdomenech } \\
\text { et al., 1975) }\end{array}$ & $\begin{array}{l}\text { Parechinus angulosus } \\
\text { (Strickland } \\
\text { et al., 1976) }\end{array}$ & $\begin{array}{c}\text { Sphaerechinus } \\
\text { granularis } \\
\text { (present work) }\end{array}$ \\
\hline 2.5 & 1.8 & 2.2 & 1.8 & 1.5 \\
\hline 5.6 & 3.3 & 2.5 & 1.9 & 4.0 \\
\hline 5.6 & 13.0 & 6.7 & 6.0 & 7.6 \\
\hline 3.7 & 4.4 & 2.0 & 2.3 & 3.6 \\
\hline 9.2 & 7.1 & 9.0 & 7.3 & 7.8 \\
\hline 7.2 & 4.8 & 4.6 & 4.2 & 4.1 \\
\hline 24.3 & 15.8 & 23.6 & 24.9 & 23.8 \\
\hline 5.4 & 3.9 & 2.8 & 3.7 & 3.1 \\
\hline 0 & 0.6 & 1.8 & 1.8 & 1.2 \\
\hline 1.5 & 3.0 & 2.8 & 1.0 & 2.0 \\
\hline 4.5 & 4.6 & 1.4 & 2.2 & 1.5 \\
\hline 0.4 & 1.7 & 0.8 & 0.9 & 0.8 \\
\hline 0.5 & 0.6 & 0.4 & 0.4 & 0.5 \\
\hline 26.8 & 24.1 & 27.4 & 29.5 & 21.6 \\
\hline 0 & 1.4 & 1.2 & 1.0 & 0.9 \\
\hline 1.8 & 10.9 & 11.2 & 11.0 & 16.2 \\
\hline 6.2 & 6.2 & 4.2 & 4.1 & 5.1 \\
\hline 28.6 & 36.4 & 39.8 & 41.5 & 38.7 \\
\hline 4.6 & 5.9 & 9.5 & 10.1 & 7.6 \\
\hline 15.0 & 2.2 & 2.4 & 2.7 & 1.3 \\
\hline
\end{tabular}

and higher therefore than that of histone H5. There is a corresponding decrease in the lysine content of $S$. granularis histone $\mathrm{H} 1$ such that the total proportion of basic residues remains approximately contant.

Gel electrophoresis of $S$. granularis histone $\mathrm{H} 1$ together with histones $\mathrm{H} 1$ and $\mathrm{H} 2 \mathrm{~B}$ from calf thymus and cytochrome $c$ as standards (Panyim \& Chalkley, 1969) indicates a molecular weight of 24000 , i.e. a molecule of about 220 residues. Preliminary sequence analysis of $S$. granularis histone H1 (W. N. Strickland \& C. Von Holt, personal communication) by using $\mathrm{CNBr}$ cleavage indicates the presence of 3 methionine residues/ molecule: on this basis the analysis of Table 1 indicates 2.0 tyrosine residues/molecule (the number observed in both $P$. angulosus and $A$. lixula $\mathrm{H} 1$ histones; Strickland et al., 1980; Puigdomenech et al., 1975) and a molecular weight of 27000 , i.e. about 250 residues. Bearing in mind the problems of molecular-weight determination of histones by gel electrophoresis, the second, larger, molecular weight is to be preferred. This is in close agreement with the value of 248 residues determined for $P$. angulosus histone H1 (Strickland et al., 1980) and considerably larger than rabbit histone H1 (213 residues; Cole, 1977) and chicken histone H5 (189 residues; Briand et al., 1980).

\section{Secondary structure}

C.d. spectra of $S$. granularis histone $\mathrm{H} 1$ were obtained over a range of ionic strengths, and the ellipticity at $222 \mathrm{~nm}$ is plotted in Fig. 1 (circles) and compared with that of calf thymus histone $\mathrm{HI}$ (triangles). Both show the increase of helicity typical for $\mathrm{H} 1$ histones to a maximum at about $1 \mathrm{M}-\mathrm{NaCl}$. On the basis of $[\theta]_{222}=-1000^{\circ}$ for random coil (Moss et al., 1976) and $-30000^{\circ}$ for a helix (Chen et al., 1974), the minimum value of $-8400^{\circ}$ represents $25 \%$ helix or 64 residues. With calf thymus histone $\mathrm{H} 1$, a minimum ellipticity of $-4000^{\circ}$ at $222 \mathrm{~nm}$ represents $10 \%$ helicity or about 23 residues of helix. The value for calf thymus histone $\mathrm{H} 1$ is close to that previously reported (Giancotti et al., 1977), but that for $S$. granularis histone $H 1$ is considerably greater than expected for a histone $\mathrm{H} 1$ molecule on the basis of homology of primary and secondary structure (Yaguchi et al., 1977; Allan et al., 1980). A check was therefore made by comparing the ellipticity at $222 \mathrm{~nm}$ of $S$. granularis histone $\mathrm{H} 1, A$. lixula histone $\mathrm{H} 1$ and chicken histone $\mathrm{H} 5$ in a single set of measurements on a second dichrograph. The value for $S$. granularis histone H1 was confirmed and that of $A$. lixula histone $\mathrm{H} 1$ found to be similar $\left(-7900^{\circ}\right)$, whereas that of the 
histone $\mathrm{H} 5$ sample was $-5000^{\circ}$, in agreement with that already published (Crane-Robinson et al., 1976). It is therefore concluded that, although the H1 histone family shows considerable sequence homology, particularly in the folding domain (Allan et al., 1980), the secondary structure content is not the same throughout.

\section{Fluorescence spectroscopy}

Fig. 1 also shows the change in intrinsic tyrosine fluorescence with ionic strength for $S$. granularis histone H1. At pH3.5 the value of $R_{\text {Tyr }}=0.28$ is typical for exposed tyrosine residues in the disordered protein (Cowgill, 1976; Giancotti et al., 1977). On folding by salt addition there is a small decrease of fluorescence to $R_{\mathrm{Tyr}} \simeq 0.2$. If the two tyrosine residues of $S$. granularis histone $\mathrm{H} 1$ are homologous with those of $P$. angulosus histone $\mathrm{H} 1$, they are situated at positions 70 and 75 , i.e. within the folding domain of the molecule (Strickland et al.,
1980; Allan et al., 1980). The relatively small change in fluorescence intensity is thus not due to their remaining disordered, and must reflect their internal situation in the tertiary structure. A tyrosine residue at position 75 would be homologous to the single tyrosine residue of calf thymus histone $\mathrm{H} 1$, which is known to exhibit an increase of fluorescence intensity to $R_{\mathrm{Tyr}}=1.3$ (Giancotti et al., 1977) as the ionic strength increases. It follows that the value of $R_{\mathrm{Tyr}}=0.2$ for $S$. granularis histone $\mathrm{H} 1$ in the folded form cannot be due to tyrosine-75 being a strong emitter, as in calf thymus histone $\mathrm{H} 1$, with tyrosine-70 having low or no emission. It follows that the tertiary structure around tyrosine-75 is not as in calf thymus histone $\mathrm{H} 1$. Although this conclusion on the non-identity of tertiary structure applies only to a limited region of the molecule, it is nevertheless in accord with the lack of secondary-structure conservation between the calf and sea-urchin histone $\mathrm{H} 1$ molecules.

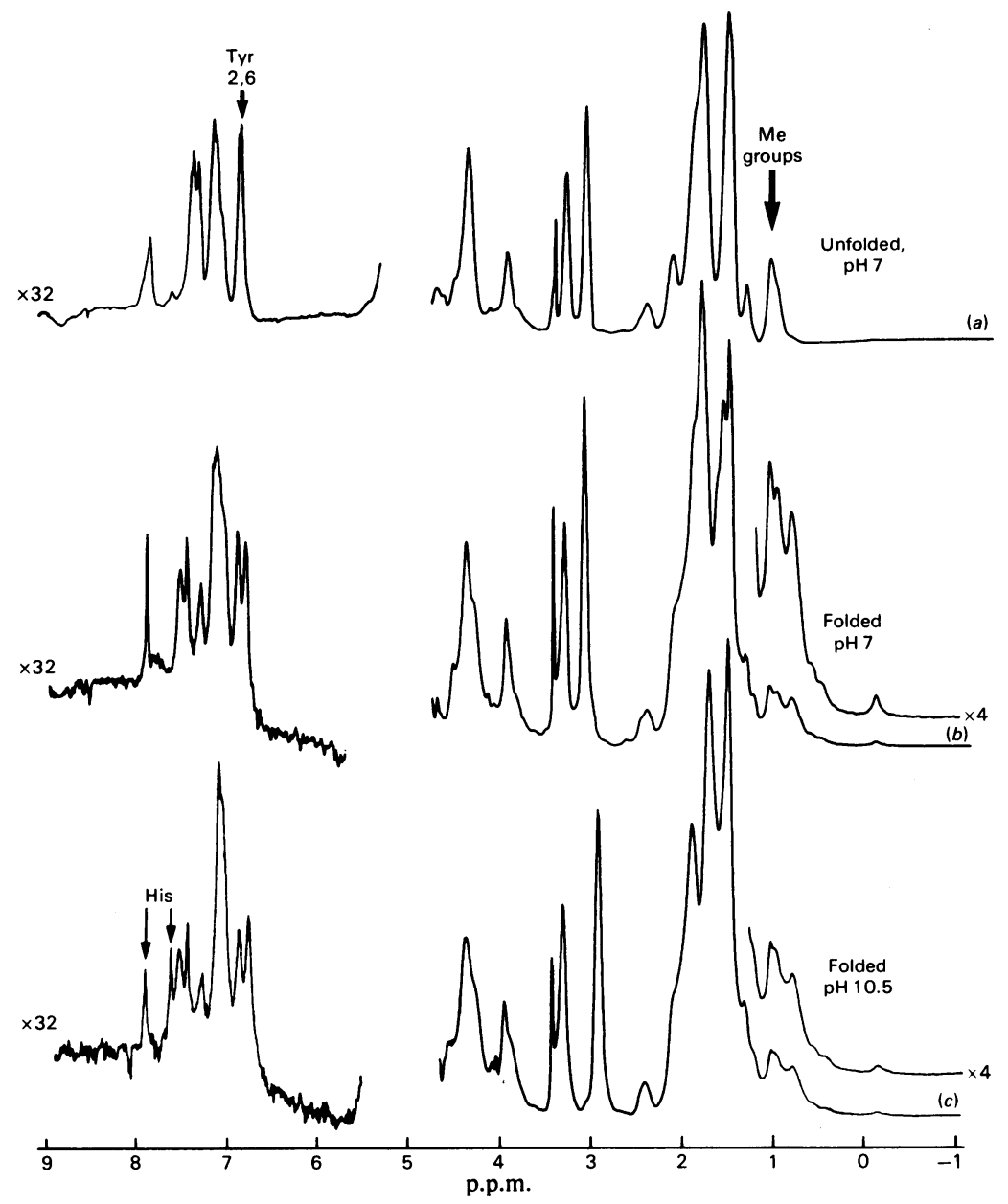

Fig. 2. $270 \mathrm{MHz}$ n.m.r. spectra of S. granularis histone $H 1$ (a) at pH 7.0 with no buffer or added salt (unfolded state) and

(b) at $\mathrm{pH} 7.0$ and (c) at $\mathrm{pH} 10.5$ with added salt (folded state), ionic strength 1.0 


\section{Nuclear-magnetic-resonance spectroscopy}

High-resolution n.m.r. spectroscopy was used to check the content of aromatic residues and to compare that tertiary structure of $S$. granularis histone $\mathrm{H} 1$ with that of $A$. lixula histone $\mathrm{H} 1$ and other $\mathrm{H} 1$ histones. The spectrum of $S$. granularis histone $\mathrm{H1}$ at $\mathrm{pH} 7.0$, in the absence of salt, is typical of a disordered protein with all residues of a single type having an identical chemical shift (see Fig. 2). In particular, the 34 methyl groups of the 17 residues of valine, leucine and isoleucine all resonate at essentially the same shift of 0.93 p.p.m. The resonance intensity of aromatic residues between 6.5 and 8.0 p.p.m. indicates that the phenylalanine:tyrosine: histidine molar proportions are probably $1: 2: 2$. This is in agreement with the amino acid analysis shown in Table 1 . On addition of $1 \mathrm{M}-\mathrm{NaCl}$ at $\mathrm{pH}$ 7.0, the spectrum of the upfield methyl groups and aromatic residues becomes complex, i.e. the protein folds. The tyrosine $C-2,6$ proton peak at 6.8 p.p.m. splits into two, confirming the presence of two tyrosine residues. At $\mathrm{pH} \mathbf{1 0 . 5}$ there is further splitting of the histidine resonance, indicating the presence of two histidine residues. In general, the detail of the spectral perturbations in both the low-field and high-field regions is very similar to that already observed for $A$. lixula histone H1 (Puigdomenech et al., 1980). Thus, although there are a significant number of compositional differences between the sperm $\mathrm{H} 1$ histones of these two sea-urchins, their tertiary structures are very similar. The aromatic and upfield methyl perturbations in the spectrum of calf thymus histone $\mathrm{H} 1$ are very different from those of the sea-urchin $\mathrm{H} 1$ histones. Although this appears to indicate differences of tertiary structure, this conclusion cannot be regarded as rigorous, since small changes in geometry and conservative replacements can give large spectral differences.

\section{Discussion}

The physical characterization described above indicates that both the secondary structure and tertiary structure of $S$. granularis histone $\mathrm{H} 1$ are very similar to those of $A$. lixula histone $\mathrm{H} 1$, despite significant compositional differences. The folding domain of $\mathrm{H} 1$ histones in which the secondary and tertiary structures are located is of approximately $\mathbf{8 0}$ residues (Hartman et al., 1977; Puigdomenech et al., 1980; Allan et al., 1980) and is centrally located. Preliminary digestion studies indicate that $S$. granularis histone $\mathrm{H} 1$ also contains a trypsinresistant domain of molecular weight approx. 9500, and is therefore similar in this respect to all the $\mathrm{H} 1$ histones so far studied (V. Giancotti, E. Russo, S. Cosimi \& C. Crane-Robinson, unpublished work). It is concluded that this domain is essentially the same in both sea-urchin sperm $\mathrm{H} 1$ histones. It is clearly a highly helical domain, and the present data indicate approx. $80 \%$ helix, which implies an 'all- $\alpha$ ' type of folding in the characterization of Levitt \& Chothia (1976). Preliminary sequence findings (W. N. Strickland \& C. Von Holt, personal communication) also indicate that most of the $N$-terminal domain is the same in $S$. granularis histone $\mathrm{H} 1$ and $P$. angulosus histone $\mathrm{H} 1$ : the only difference in the first 26 residues of $S$. granularis histone $\mathrm{H} 1$ is the insertion of glycine between residues 17 and 18 of the $P$. angulosus histone $\mathrm{H} 1$ sequence (Strickland et al., 1980). It follows that the increased arginine content of $S$. granularis histone $\mathrm{H} 1$ is located in the $C$-terminal domain of the molecule (presumably by replacement of lysine). This very basic region of histone $\mathrm{H} 1$ molecules does not fold in free solution (Hartman et al., 1977), shows much sequence variation throughout the $\mathrm{H} 1$ histone family and is thought to be the main agent for the condensation of chromatin by $\mathrm{H} 1$ histones (Allan et al., 1980).

Calf thymus histone $\mathrm{H} 1$, when folded at high ionic strength, shows a somewhat lower ellipticity than do the sea-urchin histones, a different n.m.r. spectrum and a different tyrosine fluorescence. Clearly there are significant differences in the folding domain of calf thymus histone $\mathrm{H} 1$ and the sea-urchin sperm $\mathrm{H} 1$ histones, despite the existence of a similar-sized globular domain in all these histones. The precise differences must await crystallographic study of these $\mathrm{H} 1$ histones.

The authors are grateful for support by the C.N.R., Rome, by the Ministero della Pubblica Istruzione and by the Università degli Studi di Trieste. V. G. is grateful to E.M.B.O. for the award of a Short-Term Fellowship.

\section{References}

Allan, J., Hartman, P. G., Crane-Robinson, C. \& Aviles, F. X. (1980) Nature (London) 288, 675-679

Bradbury, E. M., Carpenter, B. G. \& Rattle, H. W. E. (1973) Nature (London) 241, 123-126

Briand, G., Kmiecik, D., Sautière, P., Wouters, D., Borie-Loy, O., Biserte, G., Mazen, A. \& Champagne, M. (1980) FEBS Lett. 112, 147-151

Chen, Y. H., Yang, J. T. \& Chau, K. H. (1974) Biochemistry 13, 3350-3359

Cole, R. D. (1977) in The Molecular Biology of the Mammalian Genetic Apparatus (Ts'o, P., ed.), pp. 93-104, Elsevier/Noth-Holland, Amsterdam

Cowgill, R. W. (1976) in Biochemical Fluorescence Concepts (Chen, R. F. \& Edelhoch, H., eds.), vol. 2. pp. 441-486, M. Dekker, New York.

Crane-Robinson, C., Danby, S. E., Bradbury, E. M.. Garel, A., Kovacs, A. M., Champagne, M. \& Daune, M. (1976) Eur.J. Biochem. 67, 379-388

Vol. 195 
Finch, J. T. \& Klug, A. (1976) Proc. Natl. Acad. Sci. U.S.A. 73, 1897-1901

Geraci, G. \& Noviello, L. (1979) Cell Differ. 8, 203-210

Giancotti, V., Fonda, M. \& Crane-Robinson, C. (1977) Biophys. Chem. 6, 379-383

Greenaway, P. J. \& Murray, K. (1971) Nature (London) New Biol. 229, 233-238

Hartman, P. G., Chapman, G. E., Moss, T. \& Bradbury, E. M. (1977) Eur. J. Biochem. 77, 45-51

Johns, E. W. (1971) in Histones and Nucleohistones (Phillips, D. M. P., ed.), pp. 1-45, Plenum Press, New York

Laemmli, U. K. (1970) Nature (London) 227, 680-685

Levitt, M. \& Chothia, C. (1976) Nature (London) 261, 552-557

Littau, V. G., Burdick, C. J., Allfrey, V. G. \& Mirsky, A. E. (1965) Proc. Natl. Acad. Sci. U.S.A. 54, 12041212

Moss, T., Cary, P. D., Abercrombie, B. D., CraneRobinson, C. \& Bradbury, E. M. (1976) Eur. J. Biochem. 71, 337-350

Panyim, S. \& Chalkley, R. (1969) J. Biol. Chem. 246, 7557-7564
Puigdomenech, P., Cabre, O., Palau, J., Bradbury, E. M. \& Crane-Robinson, C. (1975) Eur. J. Biochem. 59, 237-243

Puigdomenech, P., Palau, J. \& Crane-Robinson, C. (1980) Eur. J. Biochem. 104, 263-270

Renz, M., Nehls, P. \& Hozier, J. (1977) Proc. Natl. Acad. Sci. U.S.A. 74, 1879-1883

Ris, H. \& Kubai, D. F. (1970) Annu. Rev. Genet. 4, 263-294

Strickland, W. N., Schaller, H., Strickland, M. \& Von Holt, C. (1976) FEBS Lett. 66, 322-327

Strickland, W. N., Strickland, M., Brandt, W. F., Von Holt, C., Lehmann, A. \& Wittmann-Liebold, B. (1980) Eur. J. Biochem. 104, 567-578

Suau, P., Bradbury, E. M. \& Baldwin, J. P. (1979) Eur. J. Biochem. 97, 593-602

Thomas, J. O. \& Kornberg, R. D. (1975) Proc. Natl. Acad. Sci. U.S.A. 72, 2626-2630

Van der Westhuyzen, D. R., Bohm, E. L. \& Von Holt, C. (1974) Biochim. Biophys. Acta 359, 341-345

Yaguchi, M., Roy, C., Dove, M. \& Seligy, V. (1977) Biochem. Biophys. Res. Commun. 76, 100-106 